\title{
Adoption of Mobile Commerce in the Air Travel Sector: A Qualitative Survey of Attitudes
}

\author{
Evangelos Christou* \\ Panagiotis Kassianidis** \\ Received: February 2010 | Accepted: March 2010
}

\begin{abstract}
The study presented in this paper examines the case of the customer adoption of an air travel innovation, namely delivering through mobile telephones electronic tickets as well as boarding passes and other related services for air travel, which may be viewed as an innovation in service delivery. The qualitative study reported here adopted Rogers' model of perceived innovation attributes and was augmented by Bauer's framework of perceived risk. Participants in focus groups were categorised according to their attitudes towards buying electronic tickets for air travel through mobile phones. The perceived innovation attributes were identified to be significant determinants of travellers' adoption decisions and practices. In addition, two more dimensions (compatibility with a person's values and previous experience with the product category) were found to influence travellers' adoption decisions, stressing the high complexity of the adoption decisions for mobile phone-based air travel service innovations. The findings have practical value for organisations in the air travel sector as well as for Global Distribution Systems (GDSs) and traditional travel agents.
\end{abstract}

Keywords: mobile commerce; innovation; adoption; air travel; innovation attributes

\section{Introduction}

Previous studies (Foxall, I994; Di Benedetto, I999; Joshi, Reibstein, \& Zhang, 2009; de Brentani, Kleinschmidt, \& Salomo, 2OIO) have shown that the launch of new and innovative travel products and services is an important area for both academics and practitioners. Nev-

* University of the Aegean, Department of Business Administration, Michalon 8, GR-82100, Chios, Greece. E-mail: e.christou@aegean.gr

** Technological Educational Institute of Thessaloniki, Department of Tourism Management, Greece.

E-mail: kassianp@tour.teithe.gr 
ertheless, the majority of products and services launched every year are unsuccessful at significant cost and though estimates of failure levels vary, the current trend stands (Un, Cuervo-Cazurra \& Kazuhiro, 2008). Therefore, an in-depth understanding of the reasons some people adopt an innovation and others do not, together with an identification of the factors that may influence this decision is expected to be of considerable practical value. The airlines' mobile phone-based ticketing (and peripheral services like check-in) context is one which may be of particular interest for the understanding of traveller adoption of innovations (Sigala, 2004). New services are difficult to evaluate in advance of purchase, particularly where credence qualities dominate (Menor \& Roth, 2009). In such contexts, the higher levels of uncertainty and perceived risk that face travellers may serve to emphasise the importance of effective travel marketing activity to influence and support the traveller's adoption decision (Pechlaner et al, 2002; Anckar \& D’Inkau, 2002).

The present article examines the case of the traveller's adoption of an air travel service innovation, namely delivering tickets and related services for air travel through the medium of mobile phones. The main framework for analysing the perceived attributes of an innovation has been Rogers' (I983) seminal model, with many successive researchers also including the dimension of perceived risk (e.g. Holak, I988; Lockett and Littler, I997; Tjostheim, 20O2; Christou, 2006). The above research has mainly been carried out in the context of the adoption of tangible new products. However, according to Sigala (2006) the innovation of delivering electronic tickets for air travel through mobile phones represents a complex relationship between an intangible service (high in credence qualities) and an innovative medium of service delivery (the $3 \mathrm{G}$ mobile phone). In this framework, the objectives of this paper are: to re-evaluate the applicability of Rogers' (I983) model in the context of m-commerce in the airline sector; and, to try to identify any potential additional factors that may influence a traveller's decision to adopt.

\section{Background Theory}

The adoption of innovative products and services by travellers follows similar patterns and processes with that of generic consumers' adoption of innovations (Christou \& Sigala, 2003). Past research relating to consumer adoption of innovations in both product and service markets has mostly tended to focus on identifying the characteristics of innovators and early adopters, emphasising particularly on socio-demographic and psychographic attributes of consumers (Foxall, 1994). From a psychographic viewpoint, the notion of consumer innovativeness has maintained significant interest as most authors (Johne \& Storey, I998; Tellis, Yin \& Bell, 2009) have tried to identify those individuals who display innovative behaviour and are therefore most likely to be innovators or early adopters. After identifying those individuals, then they could be considered as the clear target for marketing campaigns for new product launches. However, the measurement of innovativeness has proved difficult (Goldsmith and Hofacker, 199I; Andreou, Leonidou, Chrysostomou, Pitsillides, Samaras \& Schizas, 2005) as it became evident that experiential innovativeness could not necessarily be considered as equivalent to intrinsic innovativeness and that innovativeness in general varied across domains. Despite measurement complications, studies have tried to identify the impact of innovativeness on adoption decisions with the construct of intrinsic innovativeness being explained by the cognitive style of the consumer (Foxall 1994; Balasubramanian, B., Peterson, R. \& Jarvenpaa, 2002). In addition, Foxall and Bhate (I993a, I993b) suggest- 
ed that the notion of intrinsic or 'innate' innovativeness by itself might be too crude and that the connection between this characteristic of individuals and their adoption decision might be influenced by the product context and different levels of involvement.

Various researchers that have examined the characteristics of innovators have focused largely on socio-economic and demographic factors (Andersson \& Johansson, 2008; von Hippel, 2009). Many surveys have concluded that innovators and early adopters tend to be better educated, with higher incomes and of higher social status than the early and the late majority (LaBay and Kinnear, I98I; Lockett and Littler, I997; Barnes, 2002). Inclination to job changes has also been identified as a characteristic of innovators, as well as hours worked (Lockett and Littler, 1997). Other personal characteristics found to be important include product category involvement (Dickerson and Gentry, I983), social character (Donnelly, 1970) and opinion leadership (Rogers, 1983). Although such personal characteristics have been established as significant predictors of consumers' adoption of an innovation, an increasing body of research (Holak, I988; Lockett and Littler, I997; Christou and Sigala, 20O3) has verified that it is the perceived attributes of the innovation itself rather than the personal characteristics of the innovators and the early adopters that are the most significant predictors of the adoption decision.

To a great extend, the attributes of the innovation themselves have tended to receive rather limited consideration than the personal characteristics of innovators. Nonetheless, given that these attributes are under the control of marketers, then undoubtedly an understanding of the impact of product or service attributes on the adoption of an innovation becomes a remarkable and important research issue (Menor \& Roth, 2009). Moreover, existing research in service innovations has tended to concentrate on the processes of new service development (Johne and Storey, I998) and with some noteworthy exceptions there has been rather limited research on innovations from the travellers' perspective. In all cases where research has focused on the consumer or traveller perspective (Rugimbana and Iversen, I994; Szymigin and Bourne, I999), the framework associated with the early research by Rogers on innovations in rural societies (Rogers, 1983) has proved to be of significant value.

Pioneering Rogers' (1983) work outlined a model for evaluating the perceived attributes of an innovation that involves five constructs: relative advantage, compatibility, trialability, observability and complexity. In addition, a large number of studies have also adopted the notion of perceived risk, as described by Bauer (I960) (see Holak, I988; Lockett and Littler, I997; Sigala, 200I; Christou and Sigala, 2003). Perceived risk may be of particular relevance in a service context where consumers usually face difficulties in evaluating a service innovation prior to its adoption; therefore this appears to be the case of mobile commerce (Buellingen \& Woerter, 2004; Bouwman et al., 2008). The first four characteristics are positively related to the adoption of an innovation and the remaining two, are negatively related (Bauer, I960; Rogers, I983). The relationships between these different constructs and the nature of their influence on adoption are discussed below.

The concept of relative advantage is concerned with the extent to which an innovation is perceived by potential adopters as being superior from the idea, product or service it supersedes (Rogers, I983). The construct of relative advantage is highly domain specific, although dimensions that are found to have some generality include reduced costs and greater convenience. A key issue is that it is not the better performance of an innovation in an objective sense that matters, but rather the superiority of performance as subjectively perceived by the customer or traveller (Szymigin and Bourne, I999; Lembke, 2002; Christou \& Kassianidis, 2002a). The compatibility of an innovation is the degree to which an innovation is perceived as consistent 
with past values, experiences and the needs of the potential adopter (Rogers, 1983). An innovation that has resonance with a traveller, and where the person feels comfortable or familiar with the innovation, will have a greater possibility of adoption than an innovation which lacks these attributes. In the case of m-commerce in the airline sector, this notion of compatibility may simply refer to a traveller's acquaintance with the use of the Internet over a $3 \mathrm{G}$ or GPRS (General Packer Radio Service) mobile phone (Wang et al., 200I; Ngai \& Gunasekaran, 2007). Trialability refers to the degree to which an innovation is perceived as being trialable, usually on a limited basis prior to adoption. The opportunity to experiment with an adoption is an effective way for reducing perceived risk and thus might have a positive impact on the adoption decision (Foxall, 1994). Finally, the observability of an innovation describes the extent to which an innovation is visible and desirable to other members of a social group. The more visible an innovation (and its associated benefits), the greater the probability of adoption, simply because the gains from adoption will be more easily recognised (Rogers, 1983).

The two perceived innovation attributes that are negatively related to the adoption of an innovation are complexity and perceived risk (Jones, 2008). The complexity of an innovation is the degree to which it is perceived as relatively difficult to understand it and use it by members of a social system (Rogers, 1983). Previous research indicates that the complexity of innovations was more highly related (negatively) to their rate of adoption than any other characteristic of the innovations except relative advantage (Singh, 1966; Sigala, 2003a). In addition, uncertainty plays a role in adoption decision in the form of perceived risk (Shimp and Bearden, I982; Christou, 2003) and this construct is expected to be of considerable significance in relation to service adoption.

In the case of the air travel industry there have been a limited number of studies into the adoption of related new technologies for distribution. The relative advantage associated with the convenience of being able to receive an airline's ticket outside of travel shop's opening hours has been found to be important in both the case of the adoption of tickets delivered by traditional post (Rugimbana and Iversen, I994; Yuan \& Zhang, 2003), traditional (fixed line) telephonbased ticketing services (Lockett and Littler, 1997), as well as over the Internet (Christou and Kassianidis, 2002). By contrast, the attributes of flexibility and convenience were found to be of limited value as a source of relative advantage (Szymigin and Bourne, I999) in the case of post and traditional telephone. A major factor in travellers not adopting innovative ticketing delivery channels is the fact that they may like to interact with travel agents (Zeithaml and Gilly, 1987; Leblanc, 1990; Sigala, 2003b). In addition, perceived risk and the perceived complexity of the innovation were important negative influences on adoption in the case of both mail-delivered tickets (Rugimbana and Iversen, 1994) and traditional telephone or Internet based ticketing services (Lockett and Littler, 1997). Mobile phone ticketing has received rather less research attention because of its comparative novelty, and much of the existing research has adopted an organisational perspective (e.g. Morrison and Roberts, 1998). Where research has focused on consumer related issues, there is evidence to suggest that the patterns that emerge are similar to those of earlier work in that convenience, flexibility and control tend to encourage adoption of new channels and concerns about security and complexity discourage adoption (see, for example, Sathye, 1999). Interestingly, in a more detailed study of motivations, Barczak et al., 1997) suggest that this may be a rather simplistic view and highlight instead the importance of focusing attention on travel management philosophies as predictors of the types of channel used.

Mobile commerce for air travel products has, in comparison to in-store travel agency shopping, two main advantages. First, it offers travellers a higher level of convenience (Lin \& Wang, 
2006; Mallat et al., 2008). This stems from the fact that customers do not face any transportation and physical problems, because they can make reservations and receive tickets and booking confirmations from and at home or anywhere else (even on the move and while travelling). Second, on-line reservations and check-in over a mobile telephone save travellers time (O'Connor and Frew 2OOI; Sigala, 2006). Due to less transportation time, and less waiting and planning time, the overall time required for mobile shopping is less than the time required for in-store shopping. Another rather minor advantage of mobile shopping for air travel products is the larger geographic coverage that can be selected; furthermore, travellers can choose from a larger air travel product assortment when they shop at home or at any other place, even on the move (Vrechopoulos et al., 2003; Wang \& Cheung, 2004; Sigala, 2007).

Whereas these previous studies are indicative of the relevance of the Rogers (1983) framework in the adoption of new services, the focus of attention in most of the previous studies (Wang \& Liao, 2004; von Hippel, 2009) has been on innovations that might be considered to be dynamically continuous in that although there is novelty involved, there is nevertheless a high degree of continuity either in the nature of the service or the mode of access (e.g. mail or telephone or Internet). By contrast, the development of mobile commerce presents a much greater degree of discontinuity as a consequence of the nature of the delivery channel (the mobile telephone). While there are a number of exploratory studies in relation to Internet travel services from the traveller perspective (Sigala, 2006; Mallat, Rossi, Tuunainen \& Öörni, 2008), an in-depth analysis of the adoption decision regarding mobile commerce products for air travel is still required. Thus the research reported in this paper aimed to identify the extent to which established approaches that have been used to study the adoption of new service innovations may prove relevant in traveller decisions to adopt a major air travel service innovation with emphasis on its distribution characteristics.

\section{Research Methodology}

Due to the exploratory stage of the present research it was decided that a qualitative approach, using focus group interviews was appropriate. Focus groups are flexible by nature and allow for the exploration of consumer reactions to new product concepts (Yelland \& Gifford, 2OIO). In total, twelve focus groups were conducted each comprising between eight and ten participants. In selecting the participants, two screening criteria were employed: a) all participants had to be involved in the purchasing of air travel tickets in their own household; and b) all participants had to have some familiarity with computers, the Internet and $3 \mathrm{G}$ or GPRS mobile telephones.

The second criterion was employed as a consequence of initial exploratory research, which suggested that individuals with no awareness of Internet enabled mobile phones struggled to contribute to any discussion of $\mathrm{m}$-commerce services because such an innovation was highly incompatible with their experience. In effect, the sample was then constrained to include only those for whom compatibility was less likely to be a major issue. The three segments identified were:

Group I: Users of 3G/GPRS mobile phones that have used them to purchase airline tickets and had made use of additional mobile commerce services (like mobile check-in, mobile departure gate finder, etc.).

Group 2: Users of 3G/GPRS mobile phones that have used them to check-in or any other services with airlines but have not used their mobile phones for actual purchase of airline tickets.

Group 3: Users of 3G/GPRS mobile phones that have never used them to purchase anything. 
The above segmentation procedure was deemed necessary because it would facilitate a more meaningful dialogue between group members than if the groups had been heterogeneous. Each segment comprised two focus groups, with Group 2 (G2) and Group 3 (G3) requiring a demonstration of web pages over mobile phones from airlines that offer mobile commerce services in order to familiarise them with the topic, despite their general familiarity with the Internet and 3G/GPRS telephones.

To gain more background information on the participants they were asked to complete a questionnaire before the start of the session. The results showed that the income increased significantly from Group 3 (G3) to $G 2$ and from $G 2$ to GI, while at the same time the working hours between the three segments did not differ considerably. In terms of service category involvement, air travel service usage significantly increased from G3 to G2 and from G2 to GI; G3 and G2 own fewer telecommunications products than GI. No differences could be found across the groups in terms of consumer independent judgement making and intrinsic innovativeness - based on the scales by Manning, cited in Bruner et al. (2OOI).

All interviews were taped and transcribed, which facilitated a detailed two-stage analysis. First, the transcripts were coded; the codes were partly based on the attributes of innovations as identified in the model by Roger (1983) and partly emerged from the interviews. At a second stage, the three groups, as described above, were contrasted in order to identify possible differences.

\section{Results and Discussion}

\section{Relative advantage}

Compared to traditional telephone and traditional Internet based ticketing services, group three $\left(G_{3}\right)$ and group two $\left(G_{2}\right)$ did not identify any additional advantages, except from having the details visually available. However, they highlighted several disadvantages related to availability, accessibility and level of service. More specifically, it was mentioned that the time to log on might take longer than making using a Personal Computer connected to the Internet or a traditional phone call, while once on-line with the $3 \mathrm{G} / \mathrm{GPRS}$ phone, the transaction might take longer because the respondent felt that he had to "check and re-check" the form filled-in on-line, as he or she was worried of making mistakes.

Regarding accessibility, the use of a mobile phone was seen as leaving one more freedom with regard to where the transaction is taking place (e.g. from a bus). Traditional telephone ticketing services, as well as visiting a travel agent, were also seen more positive due to the possibility of asking questions and having a contact person.

In contrast to the above, group one (GI) identified a number of additional advantages compared to using the traditional distribution channels. Highlighted were issues such as better overview of ticketing situation (i.e. just-in-time transactions) and travel planning and the hope of cheaper tickets due to cost savings on the part of the airlines. G3 and G2 regarded human interaction as an advantage. However, participants in GI expressed their dissatisfaction with the service they are given in travel shops or over the traditional telephone, they were already familiar with using the traditional Internet (through a PC), and appeared to feel that using the mobile phone was less of a hassle.

G3 and G2 participants also expressed their view that using a mobile phone compared to other channels should lead to economic advantages due to the savings of the airlines; howev- 
er, they were aware of none significant. On the other hand, GI participants stressed the good ticket prices offered by an Internet-only airline (like easyJet and Ryanair) and the advantage of comparing ticket prices. The running costs related to conducting ticketing transactions on the mobile phonet compared to other channels elicited a wide range of responses. G3 and G2 participants mentioned that it depends on the travel agent's location, or expressed a view that the potentially lower access costs would not convince them to change to the mobile phone. GI participants stressed that off-peak time can be used to reduce the cost.

A major advantage identified by users of mobile phones was the greater control afforded to them by the use of this channel. This was in sharp contrast to respondents in $G_{3}$ and, to a lesser extent, in G2 who sensed a possible loss of control, not least because of their dependence on a technology that they did not understand and a feeling that somehow, the mobile phone might control what happened to them. Therefore, adopters do recognise significant benefits (accessibility, convenience, cost, control) from the airlines' mobile commerce services, although many expressed reservations with respect to more complex air travel services. Non-adopters retain concerns for the use of the technology, the risks involved and the loss of face to face interaction.

\section{Compatibility}

For a significant number of the non-adopters of mobile commerce, compatibility with their experience and values appeared to be a major issue. Although the initial segmentation was expected to screen out travellers for who compatibility levels would be low, many participants in $G_{3}$ were unenthusiastic users of new information and communication technology. Some of them did not feel comfortable with the use of credit cards (especially over the Internet or a mobile phone). This contributed to a noticeable degree of resistance to the 3 G/GPRS mobile phone as a distribution channel. At the same time, this group of participants emphasised their interest in using the digital television to access the Internet from home, as the television and operating the remote control were seen as familiar and thus, trustworthy. Participants in GI often referred to their busy lifestyle and the inconvenient opening hours of travel shops, as well as call centres. Typically, these people were also highly familiar with information and communications technologies and thus felt comfortable with the idea of using such systems for ticketing.

Accordingly, the degree to which an innovative channel such as a mobile phone is compatible with the individual's past experiences and values appear to have a significant impact on willingness to adopt; respondents in $G 3$ clearly felt uncomfortable with the mobile phone while those in GI were much more relaxed about new communication technologies in general and the Internet in particular.

\section{Trialability}

Only GI participants were aware that the mobile web pages of airlines contain demonstration facilities. Having seen the demonstrations, G3 and G2 participants emphasised their usefulness. This highlights the fact that trialability is crucial. However, although mobile web-based demonstrations are helpful, other opportunities for trial need to be extended to the general public. Furthermore, the fact such trials are available needs to be communicated more efficiently to potential adopters. 


\section{Observability}

The use of a mobile phone for purchasing air tickets is not visible for other members of the society; it is not even widely discussed in a social setting. This is a theme which emerged from all three groups. GI participants mentioned that they knew of others who conduct their ticketing transactions over the Internet or over a mobile phone, while this was only mentioned by one participant in $G 3$ and G2. Thus, it appears that using the mobile commerce for ticketing transactions and other services has little associated social esteem and thus the extent to which others can observe its use does not appear to be a contributor to adoption.

\section{Complexity}

The perception of the complexity involved when conducting ticketing or other service transactions on a mobile phone was inversely related to a participant's experience with the particular technology. Responses of G3 members varied, while some (after seeing the demonstration) described it as 'straightforward' and 'self explanatory', others noted that it was complicated as many on-line forms needed to be completed and this appeared a 'daunting' task. Thus, the perception of complexity seems to be related to previous experiences. Although there are different views of complexity across all three groups, clearly the first group (GI), and to a lesser extent the second group (G2), have overcome their concerns about complexity to become users. The third group $\left(G_{3}\right)$ have not and even those who recognise that mobile phone ticketing is not that complex are obviously encountering other barriers to adoption.

\section{Perceived risk}

Perceived risk is analysed here in terms of risk of error and the level of security compared to traditional Internet ticketing or visiting a travel shop. Major differences could be observed across the three groups. While GI participants felt that mobile commerce enabled them to be in control and they are unlikely to make an error, on the other hand, G3 and G2 participants found this as a daunting responsibility and appear to have more trust that travel agents are less prone to errors than they are. Therefore, it appears that segments G3 and G2 lack self-confidence when compared to GI and perceive a higher degree of risk, largely in relation to their own ability to use the channel effectively. Regarding security, G3 and GI participants engaged extensively in story telling about 'hackers', thus, it appears that fear was still a deterrent to using a mobile phone or the traditional Internet for ticketing transactions, which was far less prevalent in GI. However, participants across all segments acknowledged that this fear was irrational.

\section{Conclusion}

The study reported here focused on the innovation of delivering ticketing services through mobile telephones and re-evaluated the applicability of Roger's (I983) model. All focus group members used for data gathering were selected based on their usage of the particular distribution channel under investigation. Those who use mobile commerce to purchase airline tickets as well as for additional air travel-related services (GI) differ from those who use mobile phones for peripheral services but not ticketing ones (G2) on the basis of high- 
er income, and more use of information and communication technology. G2 (users of some mobile services but have not yet purchased anything over phone) compared to G3 participants differ in terms of higher income and a larger product related involvement.

Contrasting these three groups revealed that based on the factors of Rogers' (I983) model, G3 and G2 have very similar attitudes in terms of the advantages perceived by using a mobile phone compared to visiting travel shops or using the traditional Internet; they share a similar attitude towards the risk involved. Their attitude was far less positive than their GI counterparts. As one of the strongest influencing factors which emerged for adoption of mobile commerce to conduct ticketing transactions was compatibility with a person's values and previous experience with the product category, i.e. 3G/GPRS mobiles. Trialability was regarded as important for future adoption; however, its availability needs to be better communicated.

Aven though the Rogers framework for evaluating the perceived attributes of an innovation is a useful starting point, some other issues also emerged which need to be considered, namely societal issues and the sense of fatalism. While the former could have a negative effect on adoption, the latter seems to have a positive effect. Hence, it may be concluded that future research is needed to shed more light on the impact of societal issues and the sense of fatalism on evaluating the perceived attributes of an innovation.

\section{References}

Anckar, B. \& D’Inkau, D. (20O2). Value creation in mobile commerce: Findings from a consumer survey. Journal of Information Technology Theory and Application, 4 (I), I24-I33.

Andersson, M. \& Johansson, B. (2008). Innovation ideas and regional characteristics: Product innovations and export entrepreneurship by firms in Swedish regions. Growth \& Change, 39 (2), 193-224.

Andreou, A., Leonidou, C., Chrysostomou, C., Pitsillides, A., Samaras, C. \& Schizas, C. (2005). Key issues for the design and development of mobile commerce services and applications. International Journal of Mobile Communications, 3 (3), 303-323.

Balasubramanian, B., Peterson, R. \& Jarvenpaa, S.J. (2OO2). Exploring the implications of $\mathrm{m}$-commerce for markets and marketing. Journal of the Academy of Marketing Science, 30 (4), 348-36I.

Barczak, G., Scholder, P., and B. Pilling (1997). Developing typologies of consumer motives for use of technologically based banking services, Journal of Business Research, 38 (I), I3I9.

Barnes, S.J. (2002). The mobile commerce value chain: analysis and future developments. International Journal of Information Management, 22 (2), 9I-IO8.

Bauer, R.A. (1960). Consumer Behaviour as Risk Taking. Chicago, American Marketing Association.

Bouwman, H., Carlsson, C., Walden, P. \& Mollina-Castillo, F. (2008). Trends in mobile services in Finland 2004-2006: from ringtones to mobile internet. Info, IO (2), 75-93.

Buellingen, F. \& Woerter, M. (2004). Development perspectives, firm strategies and applications in mobile commerce. Journal of Business Research, 57 (I2), I4O2-I4O8.

Bruner, G.C., James, K.E. \& P.J. Hensel (2OOI). Marketing Scales Handbook: A Compilation of Multi-item Measures. Chicago, American Marketing Association.

Christou, E. (20O3) On-line buyers' trust in a brand and the relationship with brand loyalty: the case of virtual travel agents. Tourism Today, 3 (I), 95-IO6. 
Christou, E. (2006) A qualitative analysis of consumer attitudes on adoption of online travel services. Tourism: An International Interdisciplinary Journal, 54 (4), 323-332.

Christou, E. \& Kassianidis, P. (2OO2a) Consumers perception and adoption of online buying for travel products. Journal of Travel \& Tourism Marketing, I2(4), 93-IO7.

Christou, E. \& P. Kassianidis (2OO2b). Examining the Adoption of E-shopping for Travel Services: Determinants of Consumers' Perceptions. Information and Communication Technologies in Tourism 2002. A. Wober, A. Frew, and M. Hitz. Springer-Verlag, Wien.

Christou, E. \& M. Sigala (2003). Adoption of online shopping for holiday packages: A qualitative investigation. The Asian Waves. K.S. Chon. APac-CHRIE, Seoul.

de Brentani, U., Kleinschmidt, E.J. \& Salomo, S. (2OIO). Success in global new product development: Impact of strategy and the behavioral environment of the firm. Journal of Product Innovation Management, 27(2), I43-I6O.

Di Benedetto, A. (1999). Identifying the key success factors in new product launch. Journal of Product Innovation Management, I6(5), 53O-544. Available at SSRN: http://ssrn.com/ abstract $=893440$.

Dickerson, M.D. \& J.W. Gentry (1983). Characteristics of adopters and non adopters of home computers. Journal of Consumer Research IO(2), 225-235.

Foxall, G. (I994). Consumer initiators: both innovators and adaptors. Adaptors and Inovators. Styles of Creativity and Problem Solving. M.J. Kirton. Routledge, London.

Foxall, G.R. \& S. Bhate (I993a). Cognitive styles and innovative purchasing of 'healthy' food brands, European Journal of Marketing 27(2), 6-I7.

Foxall, G.R. \& S. Bhate (I993b). Cognitive styles of use-innovators for home computing software applications: implications for new product strategy. Technovation I3 (5), 3II-323.

Goldsmith, R.E. \& C.F. Hofacker (I99I). Measuring consumer innovativeness. Journal of the Academy of Marketing Science I9 (3), 209-22I.

Hewer, P. \& B. Howcroft (I999). Consumers distribution channel adoption and usage in the financial services industry: a review of existing approaches. Journal of Financial Services Marketing 3 (4), 344-358.

Holak, S.L. (I988). Determinants of durable adoption: an empirical study with implications for early product screening. Journal of Product Innovation Management 5 (I), 5O-69.

Johne, A. \& C. Storey (I998). New service development: a review of the literature and annotated bibliography. European Journal of Marketing 32 (3/4), I84-25I.

Jones, G. (2008). The diffusion of agricultural innovations. Journal of Agricultural Economics, I5 (3), 387-409.

Joshi, Y.V., Reibstein, D.J. \& Zhang, Z.S. (2009). Optimal entry timing in markets with social influence. Management Science, 55 (6), 926-939.

LaBay, D.G. \& T.C. Kinnear (I98I). Exploring the consumer decision process in the adoption of solar energy systems. Journal of Consumer Research 8 (2), 27I-278.

Leblanc, G. (I990). Customer motivations use and non-use of automated banking. International Journal of Bank Marketing 8 (4), 36-4O.

Lembke, J. (2OO2). Mobile commerce and the creation of a marketplace. The Journal of Policy, Regulation and Strategy for Telecommunications, 4 (3), 50-56

Lin, H.H. \& Wang, W.S. (2006). An examination of the determinants of customer loyalty in mobile commerce contexts. Information \& Management, 43 (3), 27I-282.

Lockett, A. \& D. Littler (I997). The adoption of direct telephone-based services. Journal of Marketing Management I3 (5), 79I-8II. 
Mallat, N., Rossi, M., Tuunainen, V.K. \& Öörni, A. (2008). An empirical investigation of mobile ticketing service adoption in public transportation. Personal and Ubiquitous Computing, I2 (I), 57-65.

Menor, L.J. \& Roth, A.V. (2009). New service development competence and performance: An empirical investigation in retail banking. Production \& Operations Management, I7 (3), 267-284.

Morrison, P.D. \& J.H. Roberts (I998). Matching electronic distribution channels to product characteristics: the role of congruence in consideration set formation. Journal of Business Research 4I(2), 223-229.

Ngai, E.W.T. \& Gunasekaran, A. (2007). A review for mobile commerce research and applications. Decision Support Systems, 43 (I), 3-I5.

O'Connor P. and A. Frew (2OOI). Expert Perceptions on the Future on Hotel Electronic Distribution Channels. Information and Communication Technologies in Tourism 200I. P.J. Sheldon, K.W. Wober and D.R. Fesenmaier (eds.). Springer-Verlag, Wien.

Pechlaner, H., Rienzer, H., Matzler, K. \& L. Osti (2OO2). Response Attitudes and Behaviour of Hotel Industry to Electronic Info Requests. Information and Communication Technologies in Tourism 2002. A. Wober, A. Frew, and M. Hitz.. Springer-Verlag, Wien.

Rogers, E.M. (1983). The Diffusion of Innovations. New York, The Free Press.

Rugimbana, R. \& P. Iversen (I994). Perceived attributes of postage deliveries and their marketing implications. International Journal of Bank Marketing I2 (2), 3O-35.

Tellis, G.J., Yin, E \& Bell, S. (2009). Global consumer innovativeness: Cross-country differences and demographic commonalities. Journal of International Marketing, I7 (2), I-22.

Tjostheim, I. (20O2). The Internet in Competition with the Traditional Information Sources - A Study of Vacation Planning for Package vs. Non-package Travel. Information and Communication Technologies in Tourism 2002. A. Wober, A. Frew, and M. Hitz.. SpringerVerlag, Wien.

Sathye, M. (1999). Adoption of Internet banking by Australian consumers: an empirical investigation. International Journal of Bank Marketing I7 (7), 324-334.

Shimp, T.A. \& W.O. Bearden (I982). Warranty and other extrinsic cue effects on consumers' risk perceptions. Journal of Consumer Research 9 (I), 38-46.

Sigala, M. (2OOI). Modelling e-marketing strategies: Internet presence and exploitation of Greek Hotels. Journal of Travel \& Tourism Marketing II(2/3), 83-IO3.

Sigala, M. (2003a). Competing in the Virtual Marketspace: a strategic model for developing e-commerce in the hotel industry. International Journal of Hospitality Information Technology, 3 (I), $43-60$.

Sigala, M. (2003b). Developing and Benchmarking Internet Marketing Strategies in the Hotel Sector in Greece. Journal of Hospitality \& Tourism Research, 27 (4), 375 - 4OI.

Sigala, M. (2004). Reviewing the profile and behaviour of Internet users: research directions and opportunities in tourism and hospitality. Journal of Travel and Tourism Marketing, I7 (2/3), 93-IO2.

Sigala, M. (2006). Mass customisation implementation models and customer value in mobile phones services: Preliminary findings from Greece. Managing Service Quality, I6(4), 395$42 \mathrm{O}$.

Sigala, M. (2007). Integrating Web 2.0 in e-learning environments: a socio-technical approach. International Journal of Knowledge \& Learning, 3(6), 628-648.

Singh, R.M. (I966). Characteristics of Farm Innovations Associated with the Rate of Adoption. Guelph, Ontario Agricultural Extension Education Report. 
Szymigin, I.T.D. \& H. Bourne (I999). Electronic cash: a qualitative assessment of its adoption. International Journal of Bank Marketing I7(4), I92-2O3.

von Hippel, E. (2009). Democratizing innovation: The evolving phenomenon of user innovation. International Journal of Innovation Science, I(I), 29-4O.

Vrechopoulos, A., Constantiou, I.,Sideris, I. Doukidis, G. \& Mylonopoulos, N. (2003). The critical role of consumer behaviour research in mobile commerce. International Journal of Mobile Communications, I(3), 293-34O.

Un, C., Cuervo-Cazurra, A. \& Asakawa, K. (2008). R\&D collaborations and product innovation. Journal of Product Innovation Management. Available at SSRN: http://ssrn.com/ abstract=II39I7O.

Yelland, J. \& Gifford, S.M. (2OIO). Problems of focus group methods in cross-cultural research: a case study of beliefs about sudden infant death syndrome. Australian Journal of Public Health, I9(3), 257-263.

Yuan, Y. \& Zhang, J.J. (2003). Towards an appropriate business model for m-commerce. International Journal of Mobile Communications, I(2), 35-56.

Wang, Y., Q Yu and D.R. Fesenmaier (2OOI). Defining the Virtual Tourism Community. Information and Communication Technologies in Tourism 200I. P.J. Sheldon, K.W. Wober and D.R. Fesenmaier (eds.). Springer-Verlag, Wien.

Wang, W.S. \& Cheung, W. (2004). E-Business Adoption by Travel Agencies: Prime Candidates for Mobile e-Business. International Journal of Electronic Commerce, 8(3), 43-63.

Wang, W.S. \& Liao, Y.W. (2OO4). The conceptualization and measurement of m-commerce user satisfaction. Computers in Human Behavior, 23(I), 38I-398

Zeithaml, V.A. \& M.C. Gilly (I987). Characteristics affecting the acceptance of retailing technologies: a comparison of elderly and non-elderly consumers. Journal of Retail Banking 63(I), 49-68. 